\title{
MIGRACIÓN Y VIOLENCIA CONTRA LA MUJER MIGRANTE Y REFUGIADAS
}

IMIGRAÇÃO E VIOLÊNCIA CONTRA A MULHER IMIGRANTE E REFUGIADA

IMMIGRATION AND VIOLENCE AGAINST IMMIGRANT AND REFUGEE WOMEN

\section{Ana Morell ${ }^{1}$ \\ Denise Mercedes Nuñez Nascimento Lopes Salles² Antonio Eduardo Ramires Santoro ${ }^{3}$}

Resumen: El régimen que proscribe la violencia doméstica y familiar en Brasil está establecido en la Ley número 11.340, que garantiza a toda mujer el disfrute de los derechos fundamentales inherentes a la persona humana, independientemente de su clase, raza, etnia, orientación sexual, renta, nivel cultural y educacional, edad y religión. Llamativamente, estos términos calificativos no son definidos por la norma ni la misma hace alusión a los grupos especialmente vulnerables a esta violencia, olvidando así a uno de los grupos más susceptibles de ser victimizados: mujeres migrantes y refugiadas. En este artículo se intenta, teniendo presente el objeto de la norma, conferir al derecho a disfrutar de una vida libre de violencia un sentido y alcance concreto que se inserta coherentemente con su formulación positiva en Derecho internacional. Palabras clave: Violencia doméstica y familiar, grupos especialmente vulnerables, mujeres migrantes y refugiadas.

1 Posdoctoranda en la Universidad Católica de Petrópolis; Doctora en Derecho por la Universidad Carlos III de Madrid; Máster en ciencias jurídicas por la Universidad de Stanford; Licenciada en Derecho por la Universidad de Valencia, llevando a cabo el último curso de la licenciatura en la Universidad alemana Johannes Gutenberg de Maguncia.

2 Doctora en Ciencias Políticas por el Instituto de Estudios Sociales y Políticos - IESP/UERJ, profesora del Programa de la Posgraduación en Derecho de la Universidad Católica de Petrópolis.

3 Posdoctor en Derecho por la Universidad de La Matanza; Doctor y Máster en Filosofía por la Universidad Federal de Rio de Janeiro; Máster en Derecho por la Universidad de Granada; Profesor Titular de IBMEC/RJ; Profesor de la Facultad Nacional de Derecho de la Universidad Federal de Rio de Janeiro - FND/UFRJ; Profesor del Programa de la Posgraduación en Derecho de la Universidad Católica de Petrópolis - PPGD/UCP; Abogado. 
Resumo: O regime que proíbe a violência familiar e doméstica no Brasil está estabelecido na Lei número 11.340, que garante que toda mulher desfrute dos direitos fundamentais inerentes ao ser humano, independentemente de sua classe, etnia, raça, orientação sexual, renda, nível cultural e educacional, idade e religião. Notadamente, estes termos qualificativos não são definidos pela norma e nem sequer fazem alusão a grupos especialmente vulneráveis a estes tipos de violência, esquecendo-se assim de um dos grupos mais suscetíveis à vitimização: mulheres imigrantes e refugiadas. Neste artigo tenta-se conferir sentido e abrangência concretos ao direito a desfrutar uma vida livre de violência, de modo a realizar uma inserção coerente com a formulação positiva no direito internacional Palavras-chave: Violência doméstica e familiar, grupos especialmente vulneráveis, muIheres imigrantes e refugiadas.

Abstract: The system that prohibits family and domestic violence in Brazil is established in Law 11.340, which guarantees that every women receive the fundamental rights inherent to all human beings, regardless of class, ethnicity, race, sexual orientation, income, cultural and educational level, age or religion. Notably, these qualifying terms are not defined by the norm, and do not even allude to groups that are especially vulnerable to these types of violence, thereby forgetting one of the groups most susceptible to victimization: immigrant women and refugees. This article attempts to determine the concrete meaning and scope of the right to enjoy a life free of violence, in order to perform an insertion coherent with the positive formulation in international law. Keywords: Domestic and Family violence, particularly vulnerable groups, immigrant and refugee women.

\section{INTRODUCCIÓN}

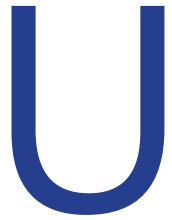

n número significativo de Estados han adoptado leyes específicas que prescriben la violencia intrafamiliar o han reformado su legislación para dar cabida a la prohibición de la violencia contra la mujer. Algunas de estas normas protegen a la mujer contra tipos concretos de violencia u otorgan mayor amparo a determinados grupos de mujeres especialmente vulnerables a la misma. Sin embargo, estas normas no siempre determinan con precisión los tipos de violencia condenada o los grupos especialmente vulnerables a la misma y su especial protección, lo que conlleva variadas soluciones judiciales ya que se atribuye a los tribunales internos la competencia para decidir si los hechos de 
los que conocen son o no violencia intrafamiliar teniendo presente el objeto de la norma. Por tanto, si bien existen diferentes respuestas en los ordenamientos de los Estados, éstas, en ocasiones, adolecen de imprecisión y no prescriben determinados tipos de violencia ni protegen a algunos grupos especialmente vulnerables a la misma.

El problema que se intenta afrontar en este artículo es si Brasil ha dado cabal cumplimiento a las obligaciones internacionales en materia de protección de la mujer migrante y refugiada contra la violencia, al paso en que se evidencia la relación existente entre migración y violencia.

El presente artículo, primero, revisa las etapas que han debido cumplirse en la formulación internacional del derecho a una vida libre de violencia, después analiza la norma brasileña y expone su falta de adecuación a los estándares internacionales, e intenta finalmente contribuir a especificar conceptos que permitan ante instancias de violencia contra la mujer otorgar a mujeres migrantes y refugiadas una protección apropiada.

\section{Formulación internacional del derecho a una vida libre de violencia}

Históricamente, a nivel internacional el propósito de garantizar la igualdad formal de derechos de los individuos aparece ligado a la protección de las personas pertenecientes a minorías ${ }^{4}$. En el siglo XVII, distintos tratados interestatales bilaterales contienen el principio de no discriminación de los miembros de minorías ${ }^{5}$ igualdad formal que fue incorporada por los ordenamientos internos durante el siguiente siglo'.

En el siglo XIX, se amplió la profundidad y el alcance de esta protección pues los tratados multilaterales, aunque seguían teniendo un alcance débil y restringido, contemplaron un mayor número de derechos y categorías de personas protegidas.

4 Commission on Security and Cooperation in Europe (comp.). Minority Rights: Problems, Parameters and Patterns in the CSCE Context. WASHINGTON D.C., 1991, p. 57.

5 Los Tratados de Oliva de 1660 entre Suecia y Polonia, de Nimega de 1678 y de Ryswick de 1697 entre Francia y Holanda y, posteriormente, el de París de 1763 entre Francia, España y Gran Bretaña, recogen el igual trato de los individuos pertenecientes a minorías. LERNER, Natan. Group Rights and Discrimination in International Law. Holanda: Kluwer, 1991, p. 7.

6 Baste mencionar el sistema de "millet" en los países musulmanes y la Primera Enmienda de la Constitución Estadounidense de 1787. Cfr CAPOTORTI, F. Estudio sobre los derechos de las personas pertenecientes a minorías étnicas, religiosas o lingüísticas. Derechos Humanos 5, Naciones Unidas, Nueva York, 1991 , p. 2. 
Así, el trato no discriminatorio por motivo de religión o raza fue reconocido a favor de todas las personas?. Los ordenamientos internos otorgaron una similar proteccións.

En el siglo XX, esta protección tuvo un gran desarrollo a nivel local e internacional bajo los auspicios de la Sociedad de Naciones y, posteriormente, de las Naciones Unidas. En 1919, tras la Gran Guerra, se estableció un limitado sistema de protección cuyo principio rector era el de la igualdad jurídica?. El igual trato, no era entonces aceptado como principio general de Derecho Internacional.

Después de la Segunda Guerra Mundial la Organización de las NU sucede en sus funciones a la Sociedad de Naciones y su tratado constitutivo reconoce los principios del respeto a los derechos humanos y la igualdad con carácter universal. La Carta afirma la igualdad de los derechos de hombres y mujeres en su preámbulo, y en su artículo primero establece, como propósito de la Organización, el desarrollo, promoción y salvaguarda del respeto a los derechos de todos sin distinciones -encomendando esta ardua tarea a la Asamblea en sus artículos 13, 55, 62 y 76. Asimismo, la Carta Internacional de Derechos del Hombre, conocida como Declaración Universal de los Derechos Humanos, de 10 de diciembre de 1948, en su segundo artículo, establece el principio de no discriminación en el disfrute de los derechos reconocidos ${ }^{10}$.

En 1946 la Comisión de la Condición Jurídica y Social de la mujer fue creada, en virtud del artículo 68 de la Carta, por el Comité Económico y Social, para

$7 \quad$ Ejemplos de ello son el Tratado de Viena de 1815 entre Austria y Países Bajos, el Acta del Congreso de Viena de 1815 firmada por Austria, Francia, Gran Bretaña, Portugal, Prusia, Rusia y Suecia, el Protocolo de 3 de febrero de 1830 elaborado en la Conferencia de Londres y suscrito por Francia, Gran Bretaña y Rusia, y el Tratado de Paris de 1856 de Austria, Francia Gran Bretaña, Prusia, Cerdeña y Turquía. LeRner, Natan. Group Rights and Discrimination in International Law. Holanda: Kluwer, 1991, p. 7.

8 Tales como la Constitución Austriaca de 1867, las Leyes Húngaras XLIV y XXX de 1868 y 1883, respectivamente, la Constitución de la Confederación Helvética de 1864 y las Leyes Belgas de 1878 y 1898. CAPOTORTI, F., pp. 3-4.

9 La introducción de mandatos de no discriminación fue debatida durante la redacción del tratado fundacional de la Sociedad de Naciones, llegándose incluso a barajar que todo Estado que quisiera integrar la Sociedad de Naciones debería respetar la igualdad de trato de sus súbditos. A pesar de que estas propuestas no prosperaron, la Sociedad de Naciones protegió a las minorías. En estos tratados figura una cláusula común que impuso obligaciones en materia de minorías a los Estados recién creados. El sistema basado en los cinco tratados de 1919-1920, se complementó por los tratados de paz impuestos a los vencidos de 1919-1923, así como por otros cuatro tratados concluidos entre 1920 y 1924, y las declaraciones unilaterales de diversos Estados al entrar a la Sociedad de Naciones entre 1921 y 1932. LeRneR, N., pp.11-14 y CAPOTORTI, F., pp. 42-43

10 La Declaración también dispuso la igualdad ante la ley, el acceso a la justicia en igualdad de condiciones, la no discriminación entre el hombre y la mujer en el matrimonio, el acceso no discriminatorio a las funciones públicas, el derecho a un salario no discriminatorio, y el derecho al igual acceso a los estudios superiores, en sus arts. 7, 10, 16, 21.2, 23 y 26.1 respectivamente, ver Carta Internacional de los Derechos del Hombre, Res. AGNU 217 A (III), de 10-12-1948. 
contribuir a la promoción de los derechos de la mujer ${ }^{11}$. Entre los años 1947 y 1962, las NU se concentraron en promover la igualdad de la mujer en la ley ${ }^{12}$. La Declaración Universal de DDHH de 1948, en sus artículos 2, 3, 5, 7, 16, 23 y 25, garantizaba a la mujer sus derechos y trataba de sentar las bases jurídicas de la igualdad de la mujer consagrada en la Carta de la ONU (Art. 55. C) ${ }^{13}$.

\section{Entre 1962 y 1975, se reconoció la importancia del desarrollo para el progreso de la mujer ${ }^{14}$. Se aprobaron entonces el Pacto Internacional de Derechos Civiles y Políticos ${ }^{15}$, el Pacto Internacional de Derechos Económicos, Sociales y Culturales'16, y la Declaración sobre la Discriminación Contra la Mujer, que consagran derechos y principios relativos a la igualdad, integridad y dignidad de la mujer incompatibles}

11 ECOSOC res. 11 (II), de 21 de junio de 1946. Las competencias iniciales de la Comisión fueron la realización de estudios sobre cómo prevenir cualquier acto de discriminación y la presentación de propuestas y recomendaciones al efecto. Su mandato fue ampliado por el ECOSOC mediante la resolución 1987/22, de 26 de mayo, para promover la igualdad, desarrollo y paz y, de nuevo, en 1996 con objeto de introducir una perspectiva de género en las actividades de la Organización y combatir la violencia contra la mujer y promover la igualdad entre hombres y mujeres, ECOSOC res. 1996/6, de 22 de julio.

12 A.G. res. 56 (I), de 11 de diciembre de 1946; A.G. res. 640 (VII), de 20 de diciembre de 1952; A.G. res. 1040 (XI), de 29 de enero de 1957; A.G. res. 1763 A (XVII), de 7 de noviembre de 1962. AA.VV. (Hannum, Hurst ed.), Guide to Human Rights Practice. $3^{a}$ ed., Nueva York, Transnational Publishers Inc., 1999, pp. 61-84.

13 A.G. res. 217 A (III), ONU Doc. A/810 p. 71 (1948).

14 E/Res/884 E, de 16 de julio de 1962 y A/RES/17777, de 7 de diciembre de 1962.

15 A.G. res. 2200A (XXI), 21 U.N. GAOR Supp. (No. 16) p. 52, ONU Doc. A/6316 (1966), 999 U.N.T.S. 171, entrada en vigor el 23 de marzo de 1976. Los artículos 2, 3, 6, 7, 9, 14, 16, 18, 23, 24 y 26 del Pacto Internacional de Derechos Civiles y Políticos garantizan los derechos de la mujer. Mediante su Observación General 18 el Comité de $\mathrm{DDHH}$, establecido para supervisar el cumplimiento de lo establecido en el Pacto y sus Protocolos, definió el término discriminación como "toda distinción, exclusión, restricción o preferencia" por motivos discriminatorios y "que tuviese por objeto o por resultado anular o menoscabar el reconocimiento, goce o ejercicio, en condiciones de igualdad, de los derechos humanos y libertades fundamentales de todas las personas". El Comité además sostiene que los Estados están obligados a adoptar disposiciones especiales para corregir la discriminación de hecho. Ver Observación General 18, de 10-11-1989. Mediante su Observación General 28, de 29-3-2000, el Comité interpreta el concepto de igualdad de derechos de hombres y mujeres, establece obligaciones estatales positivas para que ésta sea efectiva, y traslada la responsabilidad a los Estados si no actúan diligentemente en casos de discriminaciones cometidas por actores privados.

16 Pacto Internacional de Derechos Económicos, Sociales y Culturales, A.G. res. 2200A (XXI), 21 U.N. GAOR Supp. (No. 16) p. 49, ONU Doc. A/6316 (1966), 993 U.N.T.S. 3, entrada en vigor 3 de enero de 1976. El Pacto reconoce los derechos de la mujer en sus artículos 2, 3, 6, 7, 10 y 12. El CESCR, creado por el ECOSOC el 28 de mayo de 1985 para supervisar el cumplimiento de lo establecido en el Pacto, mediante su Observación General 14, definió el trato igualitario. Según el Folleto Informativo no 16 (Rev.1) del Comité, de 11-8-2005, los motivos discriminatorios presentes en el art. 2 del Pacto no son exhaustivos, y se extienden a "otras formas de discriminación injusta que repercuta negativamente en el goce de los derechos del Pacto", mientras que las medidas de discriminación positiva en favor de determinados grupos no serán consideradas discriminatorias. Los Estados tienen el deber de combatir la discriminación que lleven a cabo terceros (particulares y organismos), Observación General 14, de 11-8-2000. Otros documentos que profundizan sobre la no discriminación en el goce de los derechos enunciados en el Pacto son: Igualdad y Derechos, E/C. 12/2002/5, de 5 de febrero, e Igualdad de derechos de la mujer a una vivienda adecuada, E/C. 12/2002/4, de 4 de febrero 
con la violencia de género ${ }^{17}$. Estos instrumentos vinculan a Brasil ${ }^{18}$.

La designación por la AG de NU de 1975 como Año Internacional de la Mujer, en la primera Conferencia Mundial sobre la Condición Jurídica y Social de la Mujer celebrada en México del 19 al 2 de julio, marcó un hito pues a partir de esa fecha se incluyeron los asuntos relativos a la mujer en el Programa de la Organización ${ }^{19}$. El Decenio de las NU para la Mujer: Igualdad, Desarrollo y Paz (1976-1985) fue una iniciativa de alcance global para examinar la condición de la mujer y promover su progreso ${ }^{20}$. El desarrollo no era posible sin la mujer y el respeto a sus derechos.

En 1979 se aprobó la Convención sobre la Eliminación de todas las Formas de Discriminación contra la Mujer, en vigor desde 1981 y obligatoria para Brasil ${ }^{21}$. Por primera vez un tratado internacional definía el concepto discriminación contra la mujer ${ }^{22}$. La Segunda Conferencia Mundial sobre la Condición Jurídica y Social de la Mujer se celebró en Copenhague del 14 al 30 de julio de 1980 y giró en torno al empleo, salud y educación femeninos como requisitos para la consecución de los objetivos del Decenio de las NU para la Mujer; se exigieron medidas estatales concretas en relación con el derecho de propiedad, herencia, etc. de las mujeres ${ }^{23}$.

\section{En 1985, la Conferencia Mundial para el Examen y la Evaluación de los Logros}

17 Declaración adoptada mediante A.G. res. 48/104, de 20 de diciembre de 1993. Su implementación estatal era voluntaria y fue limitada.

18 Brasil se adhirió al Pacto Internacional de Derechos Civiles y Políticos el 24 de enero de 1992 y a sus Protocolos Facultativo el 25 de septiembre de 2009. También es Parte en el Pacto Internacional de Derechos Económicos, Sociales y Culturales desde el 24 de enero de 1992. Ver A.G. res. 2200A (XXI), 21 U.N. GAOR Supp. (No. 16) p. 52, ONU Doc. A/6316 (1966), 999 U.N.T.S. 171, entrada en vigor 23 de marzo de 1976; A.G. res. 44/128, annex, 44 U.N. GAOR Supp. (No. 49) p. 207, ONU Doc. A/44/49 (1989), entrada en vigor 11 de julio de 1991.

19 A.G. res 3010, de 18 de diciembre de 1972.

20 A.G. res 3520, de 15 de diciembre de 1975.

21 A.G. res. 34/180, 34 U.N. GAOR Supp. (No. 46) p. 193, ONU Doc. A/34/46, entrada en vigor el 3 de septiembre de 1981. Brasil está obligado por la Convención sobre la Eliminación de todas las Formas de Discriminación contra la Mujer desde el 1 de febrero de 1984. También firmó y ratificó, su Protocolo Facultativo el 13 de marzo de 2001 y el 28 de junio de 2002, respectivamente, A.G. res. 54/4, annex, 54 U.N. GAOR Supp. (No. 49) at 5, U.N. Doc. A/54/49 (Vol. I) (2000), entrada en vigor el 22 de diciembre 2000. Asimismo, ha ratificado los Convenios de la OIT No 111 relativo a la discriminación en materia de empleo y ocupación, de 25 de junio de 1958, que entró en vigor el 15 de junio de 1960 y el No 100 relativo a la igualdad de remuneración entre la mano de obra masculina y la mano de obra femenina por un trabajo de igual valor, de 29 de junio de 1951, que entró en vigor el 23 de mayo de 1953. Disponible en: https://treaties.un.org/Pages/ParticipationStatus.aspx Consultado: 2 agosto 1917.

22 A.G. res. 34/180, 34 U.N. GAOR Supp. (No. 46) p. 193, ONU Doc. A/34/46, entrada en vigor el 3 de septiembre de 1981. Su artículo primero reza: "toda distinción, exclusión o restricción basada en el sexo que tenga por objeto o por resultado menoscabar o anular el reconocimiento, goce o ejercicio por la mujer, independientemente de su estado civil, sobre la base de la igualdad del hombre y la mujer, de los derechos humanos y las libertades fundamentales en las esferas política, económica, social, cultural y civil, o en cualquier otra esfera".

23 AG res. 33/185, de 29 de enero de 1979. 
del Decenio de las NU para la Mujer: Igualdad, Desarrollo y Paz señaló los obstáculos para el logro de los objetivos del decenio y diseñó medidas concretas para superarlos. También prestó especial atención a las mujeres en situación de especial vulnerabilidad a la violencia machista ${ }^{24}$. Resultado de su celebración fue la aprobación de las Estrategias de Nairobi orientadas a la igualdad de género que se aplicaron hasta el 2000. El Informe de esta Conferencia proclamaba medidas concretas para combatir la violencia contra la mujer ${ }^{25}$. Un año antes se había adoptado la Convención contra la Tortura y otros Tratos o Penas Crueles, Inhumanos o Degradantes de $\mathrm{NU}^{26}$.

A principios de los noventa, la Comisión, el CEDAW y la $\mathrm{CDH}$, pusieron en la primera página de la agenda interestatal la violencia contra la mujer como una lacra social y no un asunto privado que exigía la debida diligencia estatal para ser combatida ${ }^{27}$. El CEDAW, establecido por la Convención sobre la Eliminación de todas las Formas de Discriminación contra la Mujer, determinó mediante su Recomendación General número 19 que la violencia contra la mujer es una forma de discriminación, y que esta violencia incluye actos que infligen daños o sufrimientos de índole física, mental o sexual, amenazas de cometer esos actos, coacción y otras formas de privación de la libertad. El Comité consideró que la violencia contra la mujer puede contravenir preceptos de la Convención, con independencia de que la violencia sea expresamente mencionada en dichas disposiciones ${ }^{28}$.

Por su parte, las Resoluciones del ECOSOC 1990/15 y 1991/18, de 24 y 30 de mayo de 1991, respectivamente, proclamaban medidas para combatir la violencia

24 ONU. Report of the World Conference to Review and Appraise the Achievements of the UN Decade for Women: Equality, Development and Peace, Nairobi, 15-16 July 1985, UN, New York, 1986.

25 A/CONF. 116/28/Rev.1, 1986 y E/RES/1987/24, de 26 de mayo de 1987.

26 Brasil firmó y ratificó la Convención contra la Tortura y otros Tratos o Penas Crueles, Inhumanos y Degradantes el 23 de septiembre de 1985 y el 28 de septiembre de 1989, respectivamente, y su Protocolo Facultativo el 13 de octubre de 2003 y el 12 de enero de 2007. Ver, A.G. res. 39/46, anexo, 39 U.N.GAOR Supp. (No. 51) p. 197, ONU Doc. A/39/51 (1984), entró en vigor el 26 de junio de 1987; A. G. res. 57/199, de 18 de diciembre de 2002, entró en vigor el 22 de junio de 2006, 42 I.L.M. 26 (2003). Disponible en: https://treaties.un.org/Pages/ParticipationStatus. aspx Consultado: 2 agosto 1917.

27 CDH res. 1995/85, de 8 de marzo; A.G. res. 48/108, de 28 de febrero de 1994; A.G. res. 49/161, de 9 de febrero de 1995; A.G. res. 50/166, de 22 de diciembre de 1995 y ECOSOC res. 1996/12, de 23 de julio.

28 El Comité también afirmó la responsabilidad de los gobiernos por actos privados si no actúan con diligencia al respecto, ver Recomendación General nº. 19, de 29-1-1992. Respecto a la necesidad de medidas especiales para promover la igualdad de facto entre hombre y mujer en los ámbitos laboral, familiar y político, ver Recomendación General n 5, de 4-3-1988, Recomendación General n 15, de 3-2-1990, Recomendación General n² 21, de 4-21994 y Recomendación General n²4, de 2-2-1999. 
contra la mujer que le negaba el disfrute de sus derechos ${ }^{29}$.

En 1993 la Declaración sobre la Eliminación de la Violencia contra la mujer, en su artículo 2, c) afirmaba que la violencia contra la mujer abarcaba "la violencia física, sexual y sicológica...tolerada por el Estado, donde quiera que ocurra" y en su artículo. 4, c) afirma que "Ios Estados deben proceder con la debida diligencia a fin de prevenir, investigar y...castigar todo acto de violencia contra la mujer" y consagra, entre otros derechos, el derecho de la mujer "al mayor grado de salud física y mental que se pueda alcanzar" (Art. 3.f) 30. Este mismo año, la Declaración y Programa de Acción de Viena, adoptada en la Conferencia Mundial sobre DDHH, celebrada entre el 14 y el 25 de junio, rechazó la violencia contra la mujer ${ }^{31}$. En 1994, la antigua Comisión de DDHH, hoy Consejo, nombró una relatora especial sobre la violencia contra la mujer que estudió sus causas y $\operatorname{costos}^{32}$.

Dos años después la Declaración y Plataforma de Acción de Beijing adoptada en la Cuarta Conferencia Mundial sobre la Mujer de las NU, celebrada entre el 4 y el 15 de septiembre, afirmó con rotundidad "los derechos de las mujeres son DDHH" y aseguró que los Estados estaban decididos a alcanzar las metas de las Estrategias de Nairobi orientadas a garantizar a las mujeres sus derechos y a tomar medidas eficaces contra sus violaciones. También se asumió el compromiso de prevenir y eliminar todas las formas de violencia contra la mujer y aplicar la Plataforma de Acción y garantizar que todas sus políticas y programas reflejasen una perspectiva de género. Brasil aprobó esta Declaración. En esta Conferencia se consolidaron los avances conquistados en las décadas previas, se proscribió globalmente la violencia contra la mujer y se afirmó la igualdad jurídica y de facto de los géneros ${ }^{33}$.

Paralelamente los Estados adoptan instrumentos e iniciativas contra la violencia de género auspiciadas por sus respectivas organizaciones internacionales de ámbito regional; así en el seno de la OEA en 1994 se adoptó la Convención Interamericana para Prevenir, Sancionar y Erradicar la Violencia contra la Mujer 29 ECOSOC res. 1990/15 y 1991/18, de 24 y 30 de mayo de 1991, respectivamente.

30 AG res. 48/104, de 20 de diciembre de 1993.

31 Declaración y Programa de Acción de Viena aprobada por la Conferencia Mundial sobre Derechos Humanos, de 25 de junio de 1993, párrs. 18 y 38.

32 CDH res. 1994/45, de 4 de marzo y CDH res. 1996/49, de 19 de abril.

33 Declaración y Plataforma de Beijing, A/CONF.177/20 (1995) y A/CONF.177/20/Add.1 (1995), párrs. 4, 22, 23, 31 y 29 , respectivamente. 
o "de Belém do Pará", que obliga a Brasil desde 1995³4. Antes Brasil, en 1992, se hizo parte en la Convención Americana de $\mathrm{DDHH}^{35}$, y en 1989 en la Convención Interamericana para Prevenir y Sancionar la Tortura ${ }^{36}$. En 1994 se creó la Relatoría sobre los Derechos de las Mujeres de la Comisión Interamericana de DDHH para garantizar los derechos de las mujeres en las Américas.

El 17 de diciembre de 1999, la AG de NU, declaró el 25 de noviembre como el Día Internacional para la Erradicación de la Violencia contra la Mujer ${ }^{37}$.

Entre el cinco y el nueve de junio del año 2000 la Asamblea General de NU celebró en Nueva York un período extraordinario de sesiones sobre los derechos de la mujer tal y como fueron concebidos en Nairobi y Beijing. Resultado de esta sesión la Asamblea adoptó el diez de junio una Declaración e Informe Final titulados "Nuevas medidas e iniciativas para la implementación de la Declaración de Beijing y su Plataforma de Acción" ${ }^{38}$. De nuevo, se consideró un tema crítico la violencia contra la mujer ${ }^{39}$. La Declaración del Milenio, adoptada en septiembre de 2000, consideró uno de sus objetivos a alcanzar la igualdad entre los géneros y la autonomía de la mujer ${ }^{40}$. El 31 de octubre el CS de NU adoptó su Resolución 1325/2000 en la que hace alusión a los compromisos adquiridos en Beijing y afirma los derechos de las mujeres durante y después de un conflicto armado ${ }^{41}$. En diciembre de este mismo año entró en vigor el Protocolo de la Convención sobre la Eliminación de todas las Formas de Discriminación contra la Mujer que permite a las personas y grupos dirigir quejas directamente al CEDAW ${ }^{42}$.

34 Convención Interamericana para Prevenir, Sancionar y Erradicar la Violencia contra la Mujer o "Convención de Belém do Pará", de 9 de junio de 1994, entró en vigor el 5 de marzo de 1995, 33 I.L.M. 1534 (1994). A partir de ahora, Convención Belém do Pará. Brasil la firmó el 9 de junio de 1994 y la ratificó el 16 de noviembre de 1995.

35 Convención Americana de los Derechos y Deberes del Hombre, de 22 de noviembre de 1969, entró en vigor el 18 de julio de 1978, SST OEA No 36. Obliga a Brasil desde el 9 de julio de 1992. Brasil se sometió a la jurisdicción de la Corte Interamericana de DDHH el 10 de diciembre de 1998.

36 Convención Interamericana para Prevenir y Sancionar la Tortura, de 9 de diciembre de 1985, entró en vigor el 28 de febrero de 1987, SST OEA No. 76. Brasil la firmó el 24 de enero de 1986 y la ratificó el 9 de junio de 1989.

37 A.G. res. 54/134, de 17 de diciembre de 1999.

38 En Report of the Secretary-General "Implementation of the Outcome of the Fourth World Conference on Women and of the Special Session of the General Assembly entitled Women 2000: Gender Equality, Development and Peace in the Twenty-first Century", ONU Doc. A/55/341 y A.G. res. 23/10, U.N. Doc. A/RES/S-23/3, de 16 de noviembre de 2000.

39 Report of the Ad Hoc Committee of the Whole of the Twenty-Third Special Session of the General Assembly, A/S23/10/Rev.1, Supp. No 3, UN, New York, 2000.

40 A.G. res. 55/2, de 8 de septiembre de 2000 , objetivo 3 ).

41 C.S. res. 1325/2000 on Women, Peace and Security, sess. $4213^{\mathrm{a}}$, de 31 de Octubre de 2000.

42 CEDAW, Protocolo de la Convención sobre la Eliminación de todas las Formas de Discriminación contra la Mujer, de 6 de octubre de 1999, entró en vigor el 22 de diciembre de 2000. 
A partir de este momento y hasta hoy se llevó a cabo la cuarta fase de la labor de las NU a favor de las mujeres a través de la celebración de conferencias mundiales que examinarían los progresos y falencias de la estrategia trazada en Beijing ${ }^{43}$. En la reunión, Examen y Evaluación Decenal, celebrada del 28 de febrero a 11 de marzo de 2005 en Nueva York, como parte del $49^{\circ}$ período de sesiones de la Comisión de la Condición Jurídica y Social de la Mujer se hizo el primer balance ${ }^{44}$. Sus resultados fueron presentados a la AG en su sexagésimo periodo de sesiones en septiembre de ese año. Para implementar las medidas encaminadas a erradicar la violencia contra la mujer se apeló a actores públicos y privados a nivel universal y local. La clave para erradicar la violencia contra la mujer se sostiene es la efectiva implementación del marco de acción y la exigencia de responsabilidad nacional en caso de incumplimiento ${ }^{45}$.

El 7 de febrero de 2006 la AG aprobó la Resolución 60/140, Seguimiento de la Cuarta Conferencia Mundial sobre la Mujer y Plena Aplicación de la Declaración y la Plataforma de Acción de Beijing y de los resultados del vigésimo tercer período extraordinario de sesiones de la $A G^{46}$. En esta Resolución hacía suyo el contenido de las propuestas alcanzadas por la Reunión de Examen y Evaluación de 2005 y enfatizaba la responsabilidad que recae sobre los Estados en la plena realización de los DDHH de las mujeres, así como la necesidad de impedir la violencia contra la mujer y su impunidad. Textualmente afirmó: "Ios Estados tienen la obligación de ejercer la diligencia debida para prevenir la violencia contra las mujeres..., proporcionar protección a las víctimas, investigar los actos de violencia...y enjuiciar y castigar a los culpables, y la omisión de hacerlo viola sus derechos..." ${ }^{47}$.

Desde 2005 las resoluciones en contra de la violencia de género de la AG y de otros órganos y organismos del Sistema de NU no han dejado de sucederse ${ }^{48}$. En 2007 la Comisión de la Condición Jurídica y Social de la Mujer se centraba en

43 Report of the Fourth World Conference on Women, Beijing, 4-15 September 1995, UN E.96.IV.13, chap. I, res. 1, annexes I-II.

44 CSW, Final Report on the 49th Session of the Commission on the Status of Women, E/2005/27-E/CN.6/2005/11, Supp. No 27, de 22 de marzo de 2005 y Corrigendum of the Final Report on the 49th Session of the Commission on the Status of Women, E/CN.6/2005/11/CORR.1, Supp. No 27, de 21 de julio de 2005.

45 CSW, Decision 48/101, de marzo de 2005 y E/CN.6/2005/L.1, de 3 de marzo de 2005.

46 A.G. Res. 60/140, Seguimiento de la Cuarta Conferencia Mundial sobre la Mujer y Plena Aplicación de la Declaración y la Plataforma de Acción de Beijing, de 7 de febrero de 2006.

47 Ídem, párr. 9.

48 A.G. res.61/143, de 30 de enero de 2007; A.G. res.62/133 y 62/134, de 7 de febrero de 2008; A.G. res.64/137, de 18 de diciembre de 2009 y A.G. res.65/187, de 23 de febrero de 2011. 
la violencia contra las adolescentes. Mientras en febrero de 2008, el Secretario General de NU lanzaba su campaña multianual encaminada a prevenir y eliminar la violencia para los años 2008-2015 Ilamada "Únete para poner fin a la Violencia Contra las Mujeres" ${ }^{49}$, en junio de ese mismo año el CS de NU volvió a repudiar y proscribir la violencia contra la mujer ${ }^{50}$.

La campaña del Secretario General de NU «Únete para poner fin a la violencia contra las mujeres», fue suscrita en agosto de 2008, con ocasión de la Conferencia de Ministros sobre Género y Asuntos de la Mujer de la UA/CEPA, por 81 altos cargos gubernamentales de 42 países africanos ${ }^{51}$. Ese mismo año, los Jefes de Estado de 17 países iberoamericanos suscribían la campaña "Di No a la Violencia contra las Mujeres" con ocasión de la XVIII Cumbre Iberoamericana celebrada en San Salvador del 29 al 31 de octubres2.

En 2009, la Comisión de la Condición Jurídica y Social de la Mujer hacía de nuevo un balance del grado de implementación de la Declaración de Beijing ${ }^{53}$. La Comisión enfatizaba en 2010 que parte de la respuesta al problema de la violencia sexista residía en que los Estados cumpliesen con el deber de debida diligencia para combatirla y en que compartiesen sus experiencias y buenas prácticas al respecto ${ }^{54}$.

En enero de 2010, el Secretario General de las NU, Ban Ki-Moon, y el Presidente de la Comisión de la UA, Jean Ping, lanzaron África ÚNETE contra la violencia de género en Addis Abeba, Etiopía, durante la Cumbre de Jefes de Estado y de Gobierno de la UA ${ }^{55}$. Mientras ÚNETE Asia-Pacífico se puso en marcha el 25 de noviembre de 2010 en Bangkok, Tailandia, ÚNETE América Latina lo hizo en Guatemala el 25 de noviembre de 2009, y se amplió justo un año más tarde para

49 ONU, End Violence, PR, UN department of Public Information DPI/ 2498, February 2008, consultado en www. un.org/en/women/endviolence

50 C.S. res. $1820 / 2008$, de 19 de junio de 2008.

51 www.unifem.org/campaigns/vaw/news-12245--13--13.html

52 La II Conferencia Iberoamericana de Género de la OEI, se celebró en junio como reunión previa a la XVIII Cumbre. OEI, Declaración del Salvador, de 6 de junio de 2008 y A.G. res. 63/155, de 30 de enero de 2009.

53 CSW, Report on the 53th Session of the Commission on the Status of Women Report, E/2009/27-E/CN.6/2009/15, Supp. No 7, de 13 de marzo de 2009.

54 Report on the 54th Session of the Commission on the Status of Women, E/2010/27-E/CN.6/2010/11, Supp. No 7, de 12 de marzo de 2010 y CSW, Decision, 54/101, de 12 de marzo de 2010.

55 www.unifem.org El decenio 2010-2020 se declaró el Decenio de la UA para la Mujer. AU/UNIFEM, Walking the Talk. Gender Equality in the African Union, 2, 14 October 2010, Addis Ababa-Etiopia. 
incluir a la región del Caribes6.

Desde 2010 hasta hoy, se lleva a cabo a nivel global una campaña, entre el 25 de noviembre y el 10 de diciembre, denominada "16 Días de Activismo por la No Violencia contra las mujeres". En 2011, la Directora Ejecutiva de ONU-Mujeres, Michelle Bachelet, propuso un programa de acción con 16 medidas concretas para poner fin a la violencia contra la mujer ${ }^{57}$. Resultado de la Conferencia de Naciones Unidas sobre el Desarrollo Sostenible, celebrada en Río de Janeiro del 20 al 22 de junio de 2012, fue la adopción de la Resolución 66/288 de la AG, que abogó por la igualdad de género, el empoderamiento de las mujeres y el cumplimiento de los compromisos adquiridos en Beijing ${ }^{58}$.

En enero de 2013 mientras la Sra. Bachellet pugnaba por el fin de la violencia contra la mujer en diferentes países africanos, la AG repudiaba la práctica de la mutilación genital femenina y declaraba el 6 de febrero como el Día de Tolerancia Cero a la mismas .

En 2015, se ampliaron los objetivos de la Declaración del Milenio, ahora denominados Objetivos de Desarrollo Sostenible o Agenda 2030, y se evaluaron los progresos alcanzados al respecto, afirmándose que "se eliminarán todas las formas de discriminación y violencia contra las mujeres y las niñas" ${ }^{60}$. Ahora la Comisión de la Condición Jurídica y Social de la Mujer se dedica de manera prioritaria a la eliminación y prevención de todas las formas de violencia contra la mujer insistiendo desde 2009 en la necesidad de la rendición de cuentas por los Estados ${ }^{61}$.

A nivel regional durante las dos últimas décadas se ha avanzado mucho. En noviembre de 2005 entraba en vigor el Protocolo Adicional a la Carta Africana de DDHH y de los Pueblos sobre los Derechos de la Mujer en África adoptado por la UA en $2003^{62}$. El Consejo de Europa, por su parte, adoptaba la Recomendación

56 www.unifem.org. Ver también www.saarc-sec.org

57 Creación y mandato en A.G. res 64/289, de 2 de julio de 2010; ver también A.G. res. 65/187, de 23-2-2011 y A.G. res. 66/132, de 19 de marzo de 2012.

58 A.G. res. 66/288, de 11 de septiembre de 2012.

59 A.G. res. 67/450, de 20 de diciembre de 2012.

60 A.G. res. 70/1, de 25 de septiembre de 2015, objetivo 5.2. Disponible en: http://www.un.org/es/comun/ docs/?symbol=A/RES/70/1. Consultado el: 12 septiembre 2017.

61 ECOSOC res. 2009/15, de 28 de julio de 2009.

62 Protocolo Adicional a la Carta Africana de DDHH y de los Pueblos sobre los Derechos de la Mujer en África, entró en vigor el 25 de noviembre de 2005, en 1 African Human Rights Law Journal 40. 
2002 (5) obligando a sus Estados a tomar una acción integral contra la violencia de género y lanzaba una campaña con idéntico propósito de noviembre de 2006 a junio de 2008 ${ }^{63}$. En sentido similar, el Consejo Ministerial de la OSCE adoptaba Decisiones que contenían prescripciones e iniciativas contra la violencia machista64. En 2002 entraba en vigor un tratado sobre los derechos de mujeres de la Asociación Surasiática para la Cooperación Regionalos. En 2004 la OEA creaba un mecanismo para la supervisión del cumplimiento de la Convención Interamericana para la prevención, castigo y erradicación de la violencia contra la mujer. El 11 de mayo de 2011, bajo los auspicios del Consejo de Europa, se adoptó el Convenio Europeo sobre Prevención y Lucha contra la Violencia contra las Mujeres y la Violencia Doméstica66. La Unión Europea considera amparada la prohibición de esta violencia en los artículos 7 y 23 de la Carta de Derechos Fundamentales de la Unión

\section{El derecho a una vida libre de violencia en la Ley brasileña $\mathbf{1 1 . 3 4 0}$}

Hoy dos tercios de los países del mundo cuentan con leyes específicas que penalizan la violencia doméstica. Muchos de ellos han incorporado disposiciones al respecto en su legislación penal, civil, de familia, laboral, extranjería y asilo y están desarrollando políticas públicas para combatir esta violencia y directrices de actuación para aquellos que en su quehacer diario la confrontan. La igualdad entre mujeres y hombres está garantizada en las constituciones de 139 países y algunas de ellas han incluido disposiciones que consagran el derecho de la mujer a una vida libre de violencia68.

Concretamente, en Brasil, el régimen que proscribe la violencia doméstica y

$63 \quad \mathrm{CM} / \operatorname{Rec}(2002) 5$, de 30 de abril de 2002.

64 OSCE, Preventing and Combating Violence Against Women, MC. DEC 15/05; OSCE, 2004 Action Plan for the Promotion of Gender Equality, MC. DEC 14/04; OSCE, Women in Conflict Prevention, Crisis Management and Post-Conflict Rehabilitation, MC. DEC 14/05, OSCE, Women's Participation in Political and Public Life, MC. DEC 7/09, www.osce.org.

65 SAARC, Convention on Preventing and Combating trafficking in women and children for prostitution, de 5 de enero de 2002.

66 Convenio Europeo sobre Prevención y Lucha contra la Violencia contra las Mujeres y la Violencia Doméstica, de 11 de mayo de 2011, CETS No 210. El Convenio establece un mecanismo de seguimiento consistente en un Grupo de Expertos en la Lucha contra la Violencia contra las Mujeres y la Violencia Doméstica (GREVIO).

67 Carta de Derechos Fundamentales de la Unión, DOCE 2000/C 364/01, de 18 de diciembre de 2000. Para jurisprudencia del TJUE sobre la materia, ver UE Caso C-205/09 Eredics and Sapi [2010] ECR 1-0000, párr. 37. También ver Consejo de Asuntos Generales, Directrices de la UE sobre violencia contra las mujeres y la lucha contra todas las formas de discriminación contra ella, de 8 de diciembre de 2008.

68 AG/CDH res. 17/23, de 19 de abril de 2011 y E/CN.6/2010/CRP. 10, de 23 de marzo de 2010. 
familiar está establecido en la Ley número 11.340, su artículo dos garantiza a toda mujer el disfrute de los derechos fundamentales inherentes a la persona humana, independientemente de su clase, raza, etnia, orientación sexual, renta, nivel cultural y educacional, edad y religión.

Llamativamente, la primera duda que surge respecto a esta enumeración de calificativos es si la norma pretendía con ella contemplar a determinados grupos especialmente vulnerables a la violencia que proscribe. La segunda incertidumbre resulta de la falta de definición normativa de estos adjetivos lo que convierte a esta enumeración en superflua pues estos términos han de ser a su vez definidos, algunos en cada caso concreto, ya que el intento de otorgarles significado, de antemano y fuera de su contexto temporal, geográfico y cultural parece un esfuerzo inútil. La no inclusión entre estos calificativos del estatus migratorio de la potencial víctima o la ausencia de una cláusula genérica al estilo de "cualquier otra condición o circunstancia" contribuyen a la inseguridad pues cabría incluso preguntarse si la norma garantiza los derechos a todas las mujeres. Así, parece que, en palabras del profesor García Amado, estamos ante "términos clave que parecen decir mucho y difícilmente significan algo" ${ }^{\prime 9}$. Lo cierto es que será el agresor quien dote de contenido a estos términos con un único significante posible: mujer objeto de violencia.

Creo que lo más extraño de la ley brasileña es que no hace mención expresa de los grupos especialmente vulnerables a la violencia que prohíbe ni prevé su particular protección, destacando la ausencia de alusión al estatus migratorio de las víctimas y el consecuente abandono de uno de los grupos más susceptibles de ser victimizados: mujeres migrantes y refugiadas.

Resulta necesario recordar que definir es decidir de ahí la gravedad de esta omisión y destacar que la misma no es conforme al acervo internacional sobre el particular pues ya en 1985, el Informe de la Tercera Conferencia Mundial sobre la Mujer, afirmó la especial protección debida a las mujeres con necesidades especiales y su especial vulnerabilidad, considerando entre ellas a refugiadas y migrantes ${ }^{70}$. Recordar que Brasil está vinculado por la Convención sobre la

70 Informe de la Tercera Conferencia Mundial sobre la Mujer. Nairobi:1985. Disponible en: http://www.cubaencuentro. 
Eliminación de todas las Formas de Discriminación contra la Mujer desde febrero de 1984, instrumento que en su artículo dos establece que los Estados proscriben la discriminación contra la mujer en todas sus formas y convienen en seguir, por todos los medios apropiados y sin dilaciones, una política encaminada a eliminar la discriminación contra la mujer. El reconocimiento del riesgo especial de las migrantes de ser victimizadas no fue olvidado tampoco en la Recomendación General 19 de 1992 del CEDAW ${ }^{71}$.

La Asamblea General consideró, en 1993, que la debida diligencia estatal en la protección de los derechos humanos conllevaba para "los países receptores o de acogida ...garantizar los derechos ...de todas las personas que se encuentren en su territorio...en especial, las trabajadoras migratorias, que son doblemente vulnerables en razón de su sexo y por ser extranjeras" y exhortó a los Estados a adoptar las medidas necesarias para la protección de los derechos de las trabajadoras migratorias ${ }^{72}$. Asimismo, el preámbulo de la Declaración sobre la Eliminación de la Violencia contra la mujer, consideró como mujeres particularmente vulnerables a la violencia a las migrantes y refugiadas y afirmó la obligación estatal de "adoptar medidas orientadas a eliminar la violencia contra las mujeres especialmente vulnerables"7з. Lo que fue reiterado por la Relatora Especial sobre Violencia contra la Mujer quien, tras afirmar que esta violencia había alcanzado proporciones tan desconocidas que la conciencia del mundo estaba conmocionada, subrayó la especial vulnerabilidad de migrantes y refugiadas ${ }^{74}$. En estas mismas fechas la redacción de la Convención Interamericana para Prevenir, Sancionar y Erradicar la Violencia contra la Mujer o Convención Belem do Para no deja lugar a dudas, ya que su artículo 9, en relación con los deberes gubernamentales, ordena a los Estados tener "especialmente en cuenta la situación de vulnerabilidad a la violencia que pueda sufrir la mujer en razón... com/derechos-humanos/derechos-de-la-mujer/documentos-conferencias-mundiales-sobre-la-mujer/nairobi-1985informe-de-la-tercera-conferencia-mundial-sobre-la-mujer. Consultado el: 25 agosto 2017

71 Recomendación General no. 19, de 29-1-1992. Artículo 6.14. Disponible en: http://www.un.org/womenwatch/daw/ cedaw/recommendations/recomm-sp.htm\#recom19 Consultado el: 1 agosto 2017

72 A.G. res. 48/110, de 20 de diciembre de 1993. Cita en preámbulo y punto 5. Disponible en: http://www.un.org/es/ comun/docs/index.asp?symbol=A/RES/48/110\&referer=http://www.un.org/depts/dhl/resguide/r48_resolutions_table_es.htm\&Lang=E. Consultado el: 22 agosto 2017

73 A.G. res. 48/104, de 20 de diciembre de 1993. Cita en artículo 4. I). Disponible en: http://www.un.org/es/comun/ docs/index.asp?symbol=A/RES/48/104\&referer=http://www.un.org/depts/dhl/resguide/r48_resolutions_table_ es.htm\&Lang=E. Consultado el: 22 agosto 2017

74 E/CN.4/1995/42, de 22 de noviembre de 1994, párrs. 47, 97, 223, 234, 295 y 299. Disponible en: https://documentsdds-ny.un.org/doc/UNDOC/GEN/G94/148/72/PDF/G9414872.pdf?OpenElement. Consultado el: 22 agosto 2017 
de su condición...de migrante, refugiada o desplazada"75.

En 1996, la Relatora Especial sobre Violencia contra la Mujer, insistía en destacar la especial vulnerabilidad de migrantes y refugiadas exhortando a los Estados a protegerlas particularmente ${ }^{76}$. La, ya mencionada, Declaración y Plataforma de Acción de Beijing, adoptada en la Cuarta Conferencia Mundial sobre la Mujer de las NU, reconoce la especial vulnerabilidad de migrantes y refugiadas, señala el compromiso estatal de reconocer esta vulnerabilidad e indica las medidas estatales a adoptar, entre ellas, "medidas especiales para eliminar la violencia contra las mujeres, en particular las especialmente vulnerables, como las...refugiadas, las desplazadas...y las trabajadoras migratorias" "7.

Curiosamente, en el Informe de la Relatora Especial sobre Brasil, de 1997, se constata la violencia contra las empleadas domésticas que su "mayoría...son mujeres migrantes" ${ }^{\prime 8}$ de otras zonas del país. La Relatora lo que documentó fue la situación de aislamiento y la consecuente vulnerabilidad de las empleadas domésticas desplazadas. También estableció que en Brasil era común la errónea percepción social de que la violencia contra la mujer sólo afectaba a las clases económicamente desfavorecidas ${ }^{79}$. Dicho de otra forma, las mujeres desplazadas, migrantes y refugiadas son siempre especialmente vulnerables a la violencia sexista pues ésta deriva de la ausencia de una red social de apoyo; por tanto, las empleadas domésticas no son las únicas vulnerables a esta violencia.

En 1998, la Comisión Interamericana hacía suya la Recomendación General 19 del CEDAW enfatizando que los Estados podrían ser responsables de los actos privados si omiten actuar con la debida diligencia estatal y recomendándoles revisar y reformar su legislación interna a efectos de que la misma refleje el desarrollo alcanzado en el Derecho internacional con relación a los derechos de la mujerso.

75 Convención Interamericana para Prevenir, Sancionar y Erradicar la Violencia contra la Mujer o Convención Belem do Para, de 9 de junio de 1994, artículo 9. Disponible en: http://www.oas.org/juridico/spanish/tratados/a-61.html. Consultado el: 2 agosto 2017

76 E/CN.4/1996/53, de 5 de febrero de 1996, párrs. 10 y 77 y ss. Disponible en: https://documents-dds-ny.un.org/doc/ UNDOC/GEN/G96/105/09/PDF/G9610509.pdf?OpenElement. Consultado el: 22 agosto 2017

77 Declaración y Plataforma de Acción de Beijing, párrs. 116, 125. c); cita en 126. d). http://www.un.org/womenwatch/ daw/beijing/pdf/BDPfA\%20S.pdf

78 E/CN.4/1997/47/Add.2, de 21 de enero de 1997, párr. 32. Disponible en: https://documents-dds-ny.un.org/doc/ UNDOC/GEN/G97/102/46/PDF/G9710246.pdf?OpenElement. Consultado el: 22 agosto 2017

79 E/CN.4/1997/47/Add.2, de 21 de enero de 1997, párr. 28. Disponible en: https://documents-dds-ny.un.org/doc/ UNDOC/GEN/G97/102/46/PDF/G9710246.pdf?OpenElement. Consultado el: 22 agosto 2017

80 Informe de la Comisión Interamericana de DDHH sobre la Condición de la Mujer en las Américas, OEA/Ser.L/V/ II.100 Doc. 17, de 13 de octubre de 1998. Disponible en: http://www.cidh.oas.org/women/Mujeres98/Capitulo5. 
Desde finales de la década de los 90 hasta hoy la Relatora Especial sobre Violencia contra la Mujer de NU ha recalcado sistemáticamente el compromiso estatal de reconocer esta vulnerabilidad específica de migrantes y refugiadas y la necesidad de adoptar medidas diferenciadas de protección ${ }^{81}$, advirtiendo en el año 2000 que "las inmigrantes son puestas por Estado en situación de vulnerabilidad agravada a la violencia debido a la falta de protección legal ${ }^{2}{ }^{\prime \prime}$. Este mismo año la Asamblea General en su Resolución caratulada "Nuevas medidas e iniciativas para la implementación de la Declaración de Beijing y su Plataforma de Acción", reconoce los obstáculos añadidos que enfrentan las refugiadas, desplazadas y migrantes en el disfrute de sus derechos comprometiéndose los Estados a adoptar un enfoque holístico al confrontar la violencia contra ellas y atender así sus diversas necesidades ${ }^{83}$.

En 2001 la Relatora, tras observar que las mujeres migrantes y refugiadas son particularmente vulnerables a la discriminación e invisibles en la sociedad ${ }^{84}$, advirtió que la discriminación basada en el género se agrava con la resultante de otros motivos de alteridad; así esta vulnerabilidad propia de determinadas identidades femeninas reduce sus recursos, aumenta su vulnerabilidad a la violencia doméstica y las expone a obstáculos adicionales para escapar de la mismas5. La Relatora Especial en el año 2003, acentuó como, correctamente, el

htm. Consultado el: 31 agosto 2017

81 E/CN.4/1997/47, de 12 de febrero de 1997, párrs. 121 y ss. y 178 y ss. Disponible en: https://documents-ddsny.un.org/doc/UNDOC/GEN/G97/104/22/PDF/G9710422.pdf?OpenElement. Consultado el: 28 agosto 2017. E/ CN.4/1998/54, de 26 de enero de 1998, párrs. 208 y ss. Disponible en: https://documents-dds-ny.un.org/doc/UNDOC/GEN/G98/102/91/PDF/G9810291.pdf?OpenElement. Consultado el: 28 agosto 2017.

82 E/CN.4/2000/68, de 29 de febrero de 2000, p.4. Disponible en: https://documents-dds-ny.un.org/doc/UNDOC/ GEN/G00/113/34/PDF/G0011334.pdf?OpenElement. Consultado el: 22 agosto 2017.

83 A.G. res. 23/10, de 16 de noviembre de 2000, párrs. 69 (j) y 98 (b). Disponible en: http://www.un.org/womenwatch/ daw/followup/ress233e.pdf. Consultado el: 1 septiembre 2017.

84 A/CONF.189/PC.3/5, de 27 de julio de 2001, párrs. 7 y 76 . En los párrafos 114 y 115, la Relatora confirma que "Immigrant women, both as dependent and independent migrants, are confronted with a complex system of multiple discrimination. Due to an intricate interaction of... discrimination in both their own communities and in the host society, women are more negatively affected by inequalities ... In most cases, existing policies and immigration laws clearly support the gender hierarchy in their families and communities, as the legal status of most immigrant women is dependent on the legal status by their husbands or fathers. Even women who are subjected to domestic violence by their husbands are not freed from this dependency and the law forces them to choose between the violence of their husbands or deportation by the national authorities". Disponible en https://daccess-ods.un.org/ access.nsf/Get?Open\&DS=A/CONF.189/PC.3/5\&Lang=E. Consultado el: 28 agosto 2017.

85 A/CONF.189/PC.3/5, de 27 de julio de 2001, párrs. 2 y 3 . Disponible en https://daccess-ods.un.org/access.nsf/ Get?Open\&DS=A/CONF.189/PC.3/5\&Lang=E. Consultado el: 28 agosto 2017. La Relatora, en el párrafo 23 de su Informe, define la discriminación múltiple afirmando: "The idea of "intersectionality" seeks to capture both the structural and dynamic consequences of the interaction between two or more forms of discrimination or systems of subordination. It specifically addresses the manner in which racism, patriarchy, economic disadvantages and other discriminatory systems contribute to create layers of inequality that structures the relative positions of women and 
Informe de la Comisión Interamericana de $\mathrm{DDHH}$, en el caso de Ana, Beatriz y Celia González Pérez, constataba como las víctimas habían sido sujeto de discriminación y victimización múltiple al no hablar el idioma de sus agresores ${ }^{86}$. La Comisión de la Condición Jurídica y Social de la Mujer, con ocasión de la celebración de su $49^{\circ}$ periodo de sesiones en 2005, evaluó la implementación a nivel interno de la Declaración y Plataforma de Acción de Beijing tras diez años desde su adopción e identificó como particularidad y reto pendiente, la especial vulnerabilidad a la violencia y la necesaria protección especial de migrantes y refugiadas- lo que fue acogido y reiterado por la Asamblea General ${ }^{87}$. La interacción de múltiples desventajas creando una dimensión única e integrada de falta de poder o subordinación de la mujer víctima de violencia doméstica migrante o refugiada fue reiterada en sus informes los años sucesivos ${ }^{88}$ - lo que confirmó respecto a las migrantes la CEDAW en 2008 ${ }^{89}$. La Relatora Especial en 2009, tras insistir en la vulnerabilidad exclusiva de migrantes y refugiadas señaló la

necesidad de adoptar medidas especiales al respecto ${ }^{\circ}$. De nuevo, la Comisión de men, races and other groups. Moreover, it addresses the way that specific acts and policies create burdens that flow along these intersecting axes contributing actively to create a dynamic of disempowerment".

86 E/CN.4/2003/75/Add.1, de 27 de febrero de 2003, párr. 1273. Disponible en: https://documents-dds-ny.un.org/doc/ UNDOC/GEN/G03/113/04/PDF/G0311304.pdf?OpenElement. Consultado el: 31 agosto 2017

87 E/2005/27-E/CN.6/2005/11, de 22 de marzo 2005, pp. 15, 22, 74, 112 y 123. Disponible en: https://documentsdds-ny.un.org/doc/UNDOC/GEN/N05/346/35/PDF/N0534635.pdf?OpenElement. Consultado el: 5 septiembre 2017; A.G. res. 60/140, de 7 de febrero de 2006. Disponible en: http://www.un.org/es/comun/docs/?symbol=A/ RES/60/140. Consultado el: 5 septiembre 2017. A.G. res. 61/143, de 19 de diciembre de 2006, párr. 8. c) f) y o) Disponible en: http://www.un.org/es/comun/docs/?symbol=A/RES/61/143. Consultado el: 5 septiembre 2017.

88 Subrayando la discriminación múltiple y particular vulnerabilidad a la violencia de determinados grupos de mujeres, entre ella migrantes y refugiadas, ver E/CN.4/2004/66, de 26 de diciembre de 2003, párr. 47. Disponible en: https://documents-dds-ny.un.org/doc/UNDOC/GEN/G04/102/02/PDF/G0410202.pdf?OpenElement. Consultado el: 1 septiembre 2017; E/CN.4/2005/72, de 17 de enero de 2005, párrs. 80 y 82 . Disponible en: https:// documents-dds-ny.un.org/doc/UNDOC/GEN/G05/102/11/PDF/G0510211.pdf?OpenElement. Consultado el: 2 septiembre 2017. E/CN.4/2006/61, de 20 de enero de 2006, párrs. 70 y ss. Disponible en: https://documents-ddsny.un.org/doc/UNDOC/GEN/G06/103/50/PDF/G0610350.pdf?OpenElement. Consultado el: 1 septiembre 2017; A/ HRC/4/34, de 17 de enero de 2007, párrs. 37. Disponible en: https://documents-dds-ny.un.org/doc/UNDOC/GEN/ G07/103/04/PDF/G0710304.pdf?OpenElement. Consultado el: 5 septiembre 2017

89 CEDAW/C/2009/WP.1/R, de 5 de diciembre de 2008, párrs. 19 y 20. Disponible en: http://tbinternet.ohchr.org/ Treaties/CEDAW/Shared\%20Documents/1_Global/CEDAW_C_2009_WP-1_R_7138_E.pdf. Consultado el: 2 septiembre 2017

90 A/HRC/11/6/Add. 5, de 27 de mayo de 2009, párrs. 15, 26, 36, 65, 67, 69, 93, 107, 115 y 123. Disponible en: https://documents-dds-ny.un.org/doc/UNDOC/GEN/G09/134/56/PDF/G0913456.pdf?OpenElement. Consultado el: 5 septiembre 2017. Concretamente en el párrafo 108, constata como "multiple systems of discrimination and hegemony result in three categories of discrimination: "targeted", such as in armed conflict against women of the "other" community; "compounded", in which an amalgam of gender and minority/marginalized group membership bars women from opportunities that would otherwise be available to them; and "structural", whereby State policies intersect with structural discrimination to increase the degree of marginalization of women based on gender, race, poverty or migrant status", afirmando en el párrafo 118 el imperativo de "of applying intersectional approaches to identify and address the effects of multiple systems of discrimination operating simultaneously, rather than address each form of discrimination in isolation of the other" lo que permite visibilizar la especial vulnerabilidad a la violencia de determinados grupos de mujeres. También en A/HRC/11/6, de 18 de mayor de 2009, párrs. 44, 75 y ss. y 84 . Disponible en http://daccess-ods.un.org/access.nsf/Get?Open\&DS=A/HRC/11/6/Add.7\&Lang=E. Consultado el: 5 
la Condición Jurídica y Social de la Mujer, con ocasión de la celebración de su $54^{\circ}$ periodo de sesiones, evaluó la implementación a nivel interno de la Declaración y Plataforma de Acción de Beijing tras quince años desde su adopción y resaltó la necesidad, debido a su particular vulnerabilidad, de adoptar medidas efectivas y específicamente dirigidas a la protección de los derechos de migrantes y refugiadas ${ }^{11}$; necesidad puesta de manifiesto asimismo por la Asamblea General y la CEDAW ${ }^{92}$. Posteriormente, la Asamblea General hizo suya la Declaración de la Comisión ${ }^{93}$ y reiteró la necesidad de esta especial protección ${ }^{94}$. Asimismo, la Asamblea tras instar a los Estados a reconocer las necesidades y vulnerabilidades de las migrantes y refugiadas, aprobó las directrices contenidas en las Estrategias y Medidas Prácticas Modelo Actualizadas para la eliminación de la violencia contra la mujer en materia de prevención del delito y justicia penal que establecen que las mismas deben incorporarse en la legislación interna y que algunos grupos de mujeres, como migrantes y refugiadas, enfrentan mayor riesgo de ser violentadas y, consecuentemente, requieren de atención, intervención y protección específicaэ5. Lo anterior estaba respaldado por lo dispuesto en la Recomendación General número 28 de la CEDAW- que fue reafirmado dos años después`.

En 2011 la Relatora Especial sobre Violencia contra la Mujer de NU era categórica:

de septiembre de 2017.

91 E/2010/27-E/CN.6/2010/11, 12 de marzo 2010, pp. 33, 46, 61 y 102. Disponible en: https://documents-dds-ny. un.org/doc/UNDOC/GEN/N10/305/79/PDF/N1030579.pdf?OpenElement. Consultado: 5 septiembre 2017.

92 La Asamblea General unos días antes insistió en reafirmar que los Estados tienen la obligación de actuar con la diligencia debida para prevenir e investigar los actos de violencia contra las mujeres, ver A.G. res. 64/141, de 18 de febrero de 2010, párr. 13. Disponible en: http://www.un.org/es/comun/docs/?symbol=A/RES/64/141. Consultado el: 1 septiembre 2017. Asimismo en el documento final de la Reunión Plenaria de Alto Nivel del sexagésimo quinto periodo de sesiones de la Asamblea General sobre los Objetivos de Desarrollo del Milenio los Estados se comprometieron a acelerar los avances hacia el logro del tercer Objetivo de Desarrollo del Milenio, la igualdad de género y el empoderamiento de la mujer, mediante, entre otras, la toma de medidas para cumplir con los objetivos de la Declaración y la Plataforma de Acción de Beijing y el reforzamiento de leyes, políticas y programas nacionales para prevenir y combatir en todas partes todas las formas de violencia contra las mujeres, ver A.G. res. 65/1, de 19 de octubre de 2010, párr. 76 a) y g). Disponible en: http://www.un.org/es/comun/docs/?symbol=A/RES/65/1. Consultado el: 6 septiembre 2017. La obligación estatal de protección especial de migrantes y refugiadas, en CEDAW/C/GC/27, de 16 de diciembre de 2010, párrs. 13 y 50. Disponible en: http://www.acnur.org/t3/fileadmin/ Documentos/BDL/2012/8335.pdf. Consultado el 1 de octubre de 2017.

93 A.G. res. 65/191, de 21 de diciembre de 2010, párr. 11. Disponible en: http://www.un.org/es/comun/docs/?symbol=A/ RES/65/191. Consultado el: 6 septiembre 2017

94 A.G. res.65/212, de 21 de diciembre de 2010, párr. 5 d). Disponible en: http://www.un.org/es/comun/docs/?symbol=A/ RES/65/212. Consultado el: 6 septiembre 2017

95 A.G. res. 65/228, de 21 de diciembre de 2010, preámbulo y párr. 11, y Anexo, párrs. 4, 10 y 18 j). Disponible en: http://www.un.org/es/comun/docs/?symbol=A/RES/65/228. Consultado el: 6 septiembre 2017

96 CEDAW/C/GC/28, de 16 de diciembre de 2010, párrs. 26 y 31 Disponible en: https://documents-dds-ny.un.org/doc/ UNDOC/GEN/G10/472/60/PDF/G1047260.pdf?OpenElement . Consultado el: 1 septiembre 2017 y CEDAW/C/ GC/32, de 14 de noviembre de 2014, párr. 34. Disponible en: https://documents-dds-ny.un.org/doc/UNDOC/GEN/ N14/627/93/PDF/N1462793.pdf?OpenElement. Consultado el: 3 septiembre 2017 
"no todas las mujeres son igualmente vulnerables a los actos y estructuras violentas", llegando a observar que "muy a menudo, las mujeres cuyos derechos son protegidos no son las mujeres cuya situación social las hace especialmente vulnerables a la violencia" 97. Igualmente, después de reafirmar el riesgo exclusivo de migrantes y refugiadas de ser víctimas de violencia98, y que la prevención y eliminación de la violencia, sus riesgos y consecuencias requiere de medidas holísticas que definan y aborden, incluido legislativamente, tanto la desigualdad y discriminación exacerbada ideológica, institucional y estructuralmente entre los géneros como en los géneros ${ }^{99}$, concluía recordando a los Estados que la violencia contra la mujer no puede resolverse con un enfoque programático único y que:

en el cumplimiento de sus obligaciones jurídicas internacionales, deben tener en cuenta que la discriminación afecta a las mujeres de diferentes maneras, dependiendo de cómo están situadas en las jerarquías sociales, económicas y culturales que impiden o comprometen la capacidad de ciertas mujeres de disfrutar de los derechos humanos universales ${ }^{100}$.

Los informes de la Relatora de años subsiguientes, hasta hoy, ilustran como la violencia contra la mujer se interrelaciona y exacerba con otros factores como la desigual desigualdad y los distintos elementos que integran la identidad, entre ellos, el estatus migratorio, de ahí, que sea necesario recalcar la particular vulnerabilidad de, entre otras, migrantes y refugiadas y la necesidad de especial protección ${ }^{101}$.

97 A/HRC/11/6, de 2 de mayo de 2011, párrs. 21 y 43. Disponible en https://documents-dds-ny.un.org/doc/UNDOC/ GEN/G11/130/22/PDF/G1113022.pdf?OpenElement. Consultado el: 19 septiembre 2017

98 A/HRC/11/6, de 2 de mayo de 2011, párrs. 47, 73, 86 y 104. Disponible en https://documents-dds-ny.un.org/doc/ UNDOC/GEN/G11/130/22/PDF/G1113022.pdf?OpenElement. Consultado el: 19 septiembre 2017.

$99 \mathrm{~A} / \mathrm{HRC} / 11 / 6$, de 2 de mayo de 2011, párrs. 20, 49, 57, 59, 70, 81 Disponible en https://documents-dds-ny.un.org/ doc/UNDOC/GEN/G11/130/22/PDF/G1113022.pdf?OpenElement. Consultado el: 19 septiembre 2017

100 A/HRC/11/6, de 2 de mayo de 2011, párr. 106; cita en párr. 101. Disponible en https://documents-dds-ny.un.org/ doc/UNDOC/GEN/G11/130/22/PDF/G1113022.pdf?OpenElement. Consultado el: 19 septiembre 2017

101 A/HRC/20/16/Add.4, de 16 de mayo de 2012, párr. 28. Disponible en http://www.ohchr.org/Documents/HRBodies/HRCouncil/RegularSession/Session20/A-HRC-20-16-Add4_en.pdf Consultado el: 19 septiembre 2017. A/ HRC/20/16/, de 23 de mayo de 2012, párrs. 26 y 66. Disponible en http://www.ohchr.org/Documents/HRBodies/HRCouncil/RegularSession/Session20/A-HRC-20-16-Add4_en.pdf Consultado el: 19 septiembre 2017. A/HRC/23/49, de 14 de mayo de 2013, párrs. 21 y 73. Disponible en http://www.ohchr.org/Documents/HRBodies/HRCouncil/ RegularSession/Session23/A_HRC_23_49_English.pdf. Consultado el: 20 septiembre 2017. A/HRC/23/49/Add.5, de 3 de junio de 2013, párrs. 4 y 68. Disponible en http://www.ohchr.org/Documents/HRBodies/HRCouncil/RegularSession/Session23/A-HRC-23-49-Add5_en.pdf. Consultado el: 20 septiembre 2017. A/HRC/26/38, de 28 de mayo de 2014, pár. 58. Disponible en https://documents-dds-ny.un.org/doc/UNDOC/GEN/G14/037/00/PDF/ G1403700.pdf?OpenElement. Consultado el: 22 septiembre 2017. A/HRC/29/27/Add.5, de 12 de junio de 2015, CEVAWG Arts. 7. 4, 7. 5 y 8. Disponible en http://www.ohchr.org/EN/lssues/Women/SRWomen/Pages/AnnualReports.aspx. Consultado el: 24 septiembre 2017. A/HRC/32/42, de 19 de abril de 2016, párr. 61. Disponible en 
Ese mismo año la Asamblea reafirmó la Declaración de la Comisión y el compromiso de lograr la aplicación de su contenido ${ }^{102}$, a la vez que reconocía la agravada vulnerabilidad y discriminación de las mujeres migrantes e instaba a los gobiernos a redoblar los esfuerzos para contrarrestaresta vulnerabilidady a adoptar "estrategias concretas y políticas dirigidas específicamente a combatirla"103. La Asamblea destacó, respecto a las mujeres refugiadas, que múltiples y concomitantes formas de discriminación conllevan una vulnerabilidad y necesidades propias ${ }^{104}$. Un ${ }^{105}$, dos $^{106}$, tres ${ }^{107}$, cuatro ${ }^{108}$, y cinco ${ }^{109}$ años después la Asamblea repetía la necesidad de prestar especial protección a migrantes y refugiadas pues sufren formas múltiples e interrelacionadas de violenta discriminación.

Este largo proceso culminó en junio de 2017 con la adopción por la CEDAW de la Recomendación General 35 que reconoce que "dado que las mujeres experimentan

https://documents-dds-ny.un.org/doc/UNDOC/GEN/G16/080/56/PDF/G1608056.pdf?OpenElement. Consultado el: 25 septiembre 2017. A/HRC/35/30, de 13 de junio de 2017, párr. 78. Disponible en http://www.ohchr.org/EN/ Issues/Women/SRWomen/Pages/AnnualReports.aspx. Consultado el: 26 septiembre 2017.

102 A.G. res. 66/132, de 19 de diciembre de 2011, párr. 2. Disponible en: http://www.un.org/es/comun/docs/?symbol=A/ RES/66/132. Consultado el: 11 septiembre 2017.

103 A.G. res. 66/128, de 19 de diciembre de 2011, párr. 7 y cita en preámbulo. Disponible en: http://www.un.org/es/ comun/docs/?symbol=A/RES/66/128. Consultado el: 12 septiembre 2017

104 A.G. res. 66/135, de 19 de diciembre de 2011, preámbulo. Disponible en: http://www.un.org/es/comun/ docs/?symbol=A/RES/66/135. Consultado el: 12 septiembre 2017

105 A.G. res. 67/185, de 20 de diciembre de 2012, párr. 8. Disponible en: http://www.un.org/es/comun/docs/?symbol=A/ RES/67/185. Consultado el: 12 septiembre 2017 y A.G. res. 67/172, de 20 de diciembre de 2012, párr. 5 d). Disponible en: http://www.un.org/es/comun/docs/?symbol=A/RES/67/172. Consultado el: 12 septiembre 2017.

106 A.G. res. 68/137, de 18 de diciembre de 2013, preámbulo. Disponible en: http://www.un.org/es/comun/ docs/?symbol=A/RES/68/137. Consultado el: 12 septiembre 2017. A.G. res. 68/140, de 18 de diciembre de 2013. Disponible en: http://www.un.org/es/comun/docs/?symbol=A/RES/68/140. Consultado el: 12 septiembre 2017 y A.G. res. 68/179, de 18 de diciembre de 2013, preámbulo. Disponible en: http://www.un.org/es/comun/ docs/?symbol=A/RES/68/179. Consultado el: 12 septiembre 2017.

107 A.G. res. 69/147, de 18 de diciembre de 2014, preámbulo. Disponible en: http://www.un.org/es/comun/ docs/?symbol=A/RES/69/147. Consultado el: 12 septiembre 2017. A.G. res. 69/150, de 18 de diciembre de 2014, párr. 9. Disponible en: http://www.un.org/es/comun/docs/?symbol=A/RES/69/150 . Consultado el: 12 septiembre 2017. A.G. res. 69/151, de 18 de diciembre de 2014, párr. 2. Disponible en: http://www.un.org/es/comun/ docs/?symbol=A/RES/69/151. Consultado el: 12 septiembre 2017. A.G. res. 69/167, de 18 de diciembre de 2014, párr. 5 d) y f). Disponible en: http://www.un.org/es/comun/docs/?symbol=A/RES/69/167. Consultado el: 12 septiembre 2017. A.G. res. 69/229, de 19 de diciembre de 2014, párr.16. Disponible en: http://www.un.org/es/comun/ docs/?symbol=A/RES/69/229. Consultado el: 12 septiembre 2017.

108 A.G. res. 70/133, de 17 de diciembre de 2015. Disponible en: http://www.un.org/es/comun/docs/?symbol=A/ RES/70/133 . Consultado el: 15 septiembre 2017. A.G. res. 70/138, de 17 de diciembre de 2015, párr. 25. Disponible en: http://www.un.org/es/comun/docs/?symbol=A/RES/70/138. Consultado el: 15 septiembre 2017. A.G. res. 70/147, de 17 de diciembre de 2015, párr. 1 . Disponible en: http://www.un.org/es/comun/docs/?symbol=A/ RES/70/147. Consultado el: 15 septiembre 2017.

109 A.G. res. 71/1, de 19 de septiembre de 2016, párr. 60, Anexo I 5. a) y b) y Anexo II. 8. i) Disponible en:. http:// www.un.org/es/comun/docs/?symbol=A/RES/71/1. Consultado el: 18 septiembre 2017. A.G. res. 71/168, de 19 de diciembre de 2016 , preámbulo y párrs. 7 y 9 . Disponible en:. http://www.un.org/es/comun/docs/?symbol=A/ RES/71/168. Consultado el: 18 septiembre 2017. A.G. res. 71/170, de 19 de diciembre de 2016, preámbulo y párrs. 10 y 11. Disponible en:. http://www.un.org/es/comun/docs/?symbol=A/RES/71/170. Consultado el: 18 septiembre 2017. A.G. res. 71/237, de 21 de diciembre de 2016, párrs. 5, 10, 11 y 20. Disponible en:. http://www.un.org/ es/comun/docs/?symbol=A/RES/71/237. Consultado el: 18 septiembre 2017 
formas múltiples e interrelacionadas de discriminación, que tienen un agravante efecto negativo... la violencia puede afectar a algunas mujeres en distinta medida, o en distintas formas, lo que significa que se requieren respuestas jurídicas y normativas adecuadas", haciendo referencia expresa a la especial vulnerabilidad de migrantes y refugiadas ${ }^{110}$.

\section{CONSIDERACIONES FINALES}

La feminización de las corrientes migratorias actuales y la prevalencia e impunidad en todas sociedades y regiones del mundo de la violencia doméstica ${ }^{111}$ y la proscripción de esta violenta discriminación por el Derecho Internacional consuetudinario y convencional -que crea obligaciones estatales de inmediato cumplimiento ${ }^{112-}$ hacen urgente la necesaria reforma de la normativa brasileña que garantiza a la mujer su derecho a una vida libre de violencia.

La especial vulnerabilidad de la mujer migrante o refugiada no deriva sólo de ser mujer o de ser migrante o refugiada sino también de la interacción de

110 Esta Recomendación General actualiza y complementa su Recomendación General 19. CEDAW/C/GC/35, de 26 de junio de 2017, párrs. 14 y 28, cita en párr. 12. Disponible en http://tbinternet.ohchr.org/_layouts/treatybodyexternal/Download.aspx?symbolno=CEDAW/C/GC/35\&Lang=en)n. Consultado el 25 de septiembre de 2017.

111 A.G. res. 65/212, de 21 de diciembre de 2010, preámbulo. Disponible en: http://www.un.org/es/comun/ docs/?symbol=A/RES/65/212. Consultado el: 6 septiembre 2017. A.G. res. 68/179, de 18 de diciembre de 2013, preámbulo. Disponible en: http://www.un.org/es/comun/docs/?symbol=A/RES/68/179. Consultado el: 12 septiembre 2017. A.G. res. 68/191, de 18 de diciembre de 2013, preámbulo. Disponible en: http://www.un.org/es/comun/ docs/?symbol=A/RES/68/191. Consultado el: 17 octubre 2017. A.G. res. 70/138, de 17 de diciembre de 2015, preámbulo. Disponible en: http://www.un.org/es/comun/docs/?symbol=A/RES/70/138. Consultado el: 15 septiembre 2017. A.G. res. 70/176, de 17 de diciembre de 2015, preámbulo. Disponible en: http://www.un.org/es/comun/ docs/?symbol=A/RES/70/176. Consultado el: 15 septiembre 2017. A.G. res. 71/237, de 21 de diciembre de 2016, párr. 20. Disponible en: http://www.un.org/es/comun/docs/?symbol=A/RES/71/237. Consultado el: 18 septiembre 2017

112 E/CN.4/2006/61, de 20 de enero de 2006, párrs. 29 y 30. Disponible en: https://documents-dds-ny.un.org/doc/UNDOC/GEN/G06/103/50/PDF/G0610350.pdf?OpenElement. Consultado el: 1 septiembre 2017; CEDAW/C/GC/35, de 26 de junio de 2017, párr. 2. Disponible en http://tbinternet.ohchr.org/_layouts/treatybodyexternal/Download. aspx?symbolno=CEDAW/C/GC/35\&Lang=en)n. Consultado el 25 de septiembre de 2017. A/72/134, de 19 de julio de 2017, párr. 79. Disponible en: http://www.un.org/ga/search/view_doc.asp?symbol=A/72/134\&Submit=Search\& Lang=E. Consultado el 29 de septiembre de 2017. Concretamente, Brasil, no sólo está obligado por la Convención sobre la Eliminación de todas las Formas de Discriminación contra la Mujer y los pronunciamientos de la CEDAW sino también por la Convención contra la Tortura y otros Tratos o Penas Crueles, Inhumanos y Degradantes y las decisiones y jurisdicción del CAT, que considera la violencia doméstica tortura cuando el Estado no protege a las víctimas, además de por los instrumentos regionales de idéntico contenido y los mandatos del Derecho internacional general. Además, la violencia contra la mujer considerada delitos internacionales o transnacionales por las Convenciones de Ginebra de 1949 y sus Protocolos Adicionales, el Estatuto de Roma, la Convención de Palermo y su Protocolo sobre trata, son conductas que Brasil se obligó a proscribir y punir desde 1957, 1992, 2002 y 2004, respectivamente. A lo anterior, se suma el, ya mencionado, voto brasileño consistentemente afirmativo de resoluciones y declaraciones que persuasivamente rechazan la violencia doméstica en foros internacionales, convirtiéndose en su contenido en orientaciones programáticas para Brasil que deberá adoptar medidas y normas específicas y coherentes con el sentido de su voto. 
ambas condiciones y los Estados, Brasil entre ellos, deben visibilizarla, conocerla, reconocerla y combatirla adecuadamente, es decir, deben otorgar a sus víctimas especial protección. Por ejemplo, una mujer víctima de violencia doméstica originaria del país en el que reside si logra escapar de la violencia lo más probable es que lo haga con sus hijos dentro de esas mismas fronteras; por el contrario, una mujer migrante o refugiada víctima de violencia doméstica con hijos menores de edad, aún si logra escapar de la violencia, no podrá salir de la cárcel en la que se transforman las fronteras nacionales en aquellos Estados en los que se exige la autorización paterna para que los menores puedan abandonar el país privándola así, simultáneamente, del auxilio de su red de apoyo originaria. En el caso de la migrante o refugiada la ausencia de una red social de apoyo no sólo la hace más vulnerable a la violencia sexista sino también más impotente para escapar de la misma y esto le sucede no por ser mujer o por ser extranjera si no por ser una mujer migrante o refugiada.

La especial vulnerabilidad de la mujer migrante o refugiada a la violencia de género no la comparten las mujeres nacionales del Estado en que reside, tampoco los migrantes o refugiados varones que por definición no son víctimas de esta violencia; su particular vulnerabilidad la hace merecedora de especial protección estatal. Los Estados, no pueden alegar que cumplen con la debida diligencia estatal en la protección de los derechos de la mujer migrante o refugiada si, por ejemplo, la ponen en la situación de tener que elegir entre ser víctima de violencia doméstica o abandonar a sus hijos en manos de su agresor.

Lo anterior exige que Brasil revise, modifique o derogue todas las normas, políticas y prácticas contrarias a la prohibición de violencia contra la mujer, así como que adopte todas las medidas positivas de todo tipo conducentes a su observancia. Concretamente, en primer lugar, es perentorio modificar la Ley 11.340 para en su texto dar cabal cumplimiento al mandato internacional de especial protección de los grupos particularmente vulnerables a la violencia que proscribe, entre ellos, mujeres migrantes y refugiadas. Esta norma, conforme a los mandatos y recomendaciones internacionales debería prever:

- la información, formación, concienciación, dotación y financiación idónea de personal involucrado en identificar, prevenir y combatir la violencia doméstica contra migrantes y refugiadas 
- un esfuerzo preventivo consistente en el acercamiento conjunto, coordinado y respetuoso de sus derechos a estos grupos vulnerables por parte de los poderes estatales y agentes sociales, con la consideración del riesgo a la violencia doméstica y la promoción de la seguridad.

- la consentida y confidencial recopilación, análisis, intercambio, remisión y diseminación de datos sobre violencia doméstica contra mujeres migrantes y refugiadas por los servicios involucrados con respeto a la privacidad de las víctimas y con objeto de estudiar, evidenciar, concienciar al respecto y combatir esta discriminación concomitante agravada.

- la asesoría y asistencia gratuita de todo tipo, habitacional, laboral, jurídica, consular, médica, sicológica, educativa, lingüística, etc., en un idioma que migrantes, regulares e irregulares, y refugiadas víctimas de violencia comprendan y respetuosa de su cultura, también en aquellos casos en que ellas se encuentren privadas de libertad consecuencia de la comisión de delitos.

- la orden de expulsión y alejamiento del agresor del lugar de residencia de la víctima migrante o refugiada

- los refugios adaptados a sus necesidades particulares

- la persecución penal de oficio en casos de violencia contra migrantes, regulares e irregulares, y refugiadas.

- la tipificación específica, de alcance extraterritorial, de la violencia doméstica resultante de prácticas culturales, tradicionales o religiosas.

- el refuerzo de las sanciones legales, los recursos civiles y las reparaciones de las víctimas Además, resulta ineludible la revisión basada en los derechos y con perspectiva de género de otros cuerpos legales, de tal forma que, entre otros, se garantice que:

- la concesión, vigencia o renovación de visados de entrada, permanencia y trabajo en el país de la mujer migrante y sus hijos o del estatuto de refugiado a ella y sus hijos no dependa de la concesión de estos visados o estatuto a su agresor, incluso en supuestos de matrimonios ficticios, así como que la entrega de la documentación de la mujer y sus hijos sea hecha con celeridad y únicamente a ella y a solicitud de la misma. 
- la denuncia de la violencia no conlleve el arresto, confiscación de pasaporte y/o deportación de las víctimas de la violencia y/o, en el supuesto de matrimonios ficticios, la imposición de penas desproporcionadas o que ignoren si la víctima auténticamente consintió o no a tal matrimonio.

-la denuncia de la violencia en supuestos de tráfico de personas conlleve sin excepción la activación del proceso penal y salvaguardando la no penalización de la víctima por participar en actividades delictivas o su situación ilícita en el país, así como, según ella desee, su repatriación inmediata, segura y coordinada con su país de origen o su protección como testigo, asistencia en su reubicación física y laboral y la posibilidad de solicitar la residencia temporal o permanente en el país.

- la concesión, mantenimiento o renovación de visados de entrada, permanencia y trabajo en el país de la trabajadora migrante y sus hijos no dependa del empleador violento, así como que la entrega de la documentación sea hecha con rapidez y únicamente a ella y a solicitud de la misma.

- la denuncia de la violencia no conlleve el arresto, confiscación de pasaporte y deportación de la migrante regular o irregular y sus hijos.

- la expulsión y/o prohibición de entrada en el país del agresor no nacional - la concesión de divorcio ipso facto en casos de violencia doméstica sin exigencia de cumplimiento de plazos u otras condiciones

- la concesión de la patria potestad y custodia de los hijos menores a la mujer víctima de violencia doméstica, así como del nasciturus desde antes del alumbramiento.

- la denegación al agresor de visitas de los hijos menores de la mujer víctima de violencia doméstica o la concesión de visitas supervisadas por la autoridad y regladas respecto, entre otros, al lugar, el costo y la ausencia de contacto entre la mujer víctima de violencia y su agresor.

- la libertad de movimiento y la libre elección de residencia de la mujer víctima de violencia con o sin sus hijos menores

- el derecho a viajar al extranjero y a abandonar el país de la mujer víctima de violencia con o sin sus hijos menores 
- la prohibición en los medios de comunicación de toda manifestación cosificadora de las mujeres migrantes y refugiadas, incluidas las realizadas vía medios telemáticos - la especial penalización de manifestaciones de discriminación múltiple laboral, migratoria, etc.

Concluir recordando que una modificación legislativa adecuada puede habilitar el ejercicio de los derechos, pero su goce efectivo exige que las modificaciones propuestas deban ir acompañadas de medidas que aseguren la superación de las falencias de las personas y de las instituciones encargadas de implementarlas, de acciones en contra de la discriminación histórica de la mujer.

\section{REFERENCIAS DE LAS FUENTES CITADAS}

CAPOTORTI, F. Estudio sobre los derechos de las personas pertenecientes a minorías étnicas, religiosas o lingüísticas. Derechos Humanos 5, Naciones Unidas, Nueva York, 1991.

COMMISSION ON SECURITY AND COOPERATION IN EUROPE (comp.). Minority Rights: Problems, Parameters and Patterns in the CSCE Context. WASHINGTON D.C., 1991, p. 57. GARCÍA AMADO, J. A. Escritos sobre Filosofía del Derecho. Colombia: Rosaristas, 1999.

HANNUM, Hurst (ed.) Guide to Human Rights Practice. 3. ed. Nueva York: Transnational Publishers Inc., 1999.

LERNER, Natan. Group Rights and Discrimination in International Law. Holanda: Kluwer, 1991.

ONU. Report of the World Conference to Review and Appraise the Achievements of the UN Decade for Women: Equality, Development and Peace, Nairobi, 15-16 July 1985, UN, New York, 1986.

ONU. End Violence, PR, Naciones Unidas department of Public Information DPI/ 2498, February 2008, consultado en www.un.org/en/women/endviolence

Recebido em: fevereiro/2018

Aprovado em: março/2018 